\title{
Epithelial-myoepithelial carcinoma of the supraclavicular region: An unusual cause of dyspnea
}

\author{
Ibrahim Hira, ${ }^{1}$ (]) Mustafa Sahin, ${ }^{2}$ (D) Ali Bayram, ${ }^{2}$ (D) Altan Kaya, ${ }^{2}$ (D) Hatice Karaman, ${ }^{3}$ \\ Ibrahim Ozcan ${ }^{2}$ \\ ${ }^{1}$ Department of Otorhinolaryngology Head and Neck Surgery, Ankara Dr. Hulusi Alatas Elmadag State Hospital, Ankara, Turkey \\ 2Department of Otorhinolaryngology Head and Neck Surgery, Health Sciences University, Kayseri Training and Research Hospital, Kayseri, Turkey \\ ${ }^{3}$ Department of Medical Pathology, Health Sciences University, Kayseri Training and Research Hospital, Kayseri, Turkey
}

\begin{abstract}
Epithelial-myoepithelial carcinoma (EMC) is an extremely rare disease and usually develops in major salivary glands, such as the parotid gland. EMC is regarded as a low grade-malignancy tumor, and the treatment protocol involves wide surgical excision with secure clear margins although postoperative radiotherapy is generally performed to reduce local recurrence. The present study aims to report a case of EMC with a supraclavicular location due to its rare occurrence and atypical location.
\end{abstract}

Keywords: Dyspnea; epithelial-myoepithelial carcinoma; supraclavicular region.

Cite this article as: Hıra I, Sahin M, Bayram A, Kaya A, Karaman H, Ozcan I. Epithelial-myoepithelial carcinoma of the supraclavicular region: an unusual cause of dyspnea. North Clin Istanb 2019;6(4):404-406.

$E^{\mathrm{p}}$ pithelial-myoepithelial carcinoma (EMC) is an extremely rare disease, which was first reported by Donath et al. in 1972 [1]. EMC includes two cell groups with distinct features, which are the key to diagnosis. EMC is a rare tumor representing approximately $1 \%$ of the salivary gland tumors [2]. EMC usually develops in major salivary glands, such as the parotid gland, but infrequently occurs in the maxillary sinus, trachea, tongue, lung and larynx [3-5].

\section{CASE REPORT}

A 58-year-old woman presented with dyspnea and painless mass on the left supraclavicular area that had been present for a year. The patient's history included Diabetes Mellitus (DM) for two years and right hemithyroidectomy 15 years ago, which was the cause of benign thyroid nodule. There is mild fullness on the examination of the nasopharynx. Left vocal cord was observed paramedian fixation. The result of the nasopharynx biopsy of the patient was lymphoid hyperplasia. Neck ultrasonography (USG) showed a mass of $42 \times 26 \mathrm{~mm}$ in the left supraclavicular region that was seen to be blooded with Doppler USG. Fine needle aspiration biopsy was reported as suspicious cytology. $\mathrm{Ca}, \mathrm{PTH}$, anti-TPO values were normal. Upper gastrointestinal system endoscopy was carried out. The result of the biopsy was superficial gastritis. Neck computed tomography (CT) and magnetic resonance imaging (MRI) were performed (Fig. 1, 2).

An excisional biopsy was planned for the patient. As an intraoperative problem, it was seen that the left recurrent nerve was completely swollen by the tumor. Approximately $6 \times 4 \times 3 \mathrm{~cm}$ mass was totally excised. The pathological result was reported epithelial-myoepithelial carcinoma; the surgical margin was positive. Chemoradiotherapy was planned because of positive margin and big tumor size. No recurrence was detected in nearly

Received: March 05, 2018 Accepted: September 12, 2018 Online: July 02, 2019

Correspondence: Dr. Ibrahim HIRA. Ankara Dr. Hulusi Alatas Elmadag Devlet Hastanesi, Kulak Burun Bogaz ve Bas Boyun Cerrahisi Klinigi, Ankara, Turkey.

Tel: +90 3128631041 e-mail: dr.ibrahimhira@gmail.com

(c) Copyright 2019 by Istanbul Provincial Directorate of Health - Available online at www.northclinist.com 

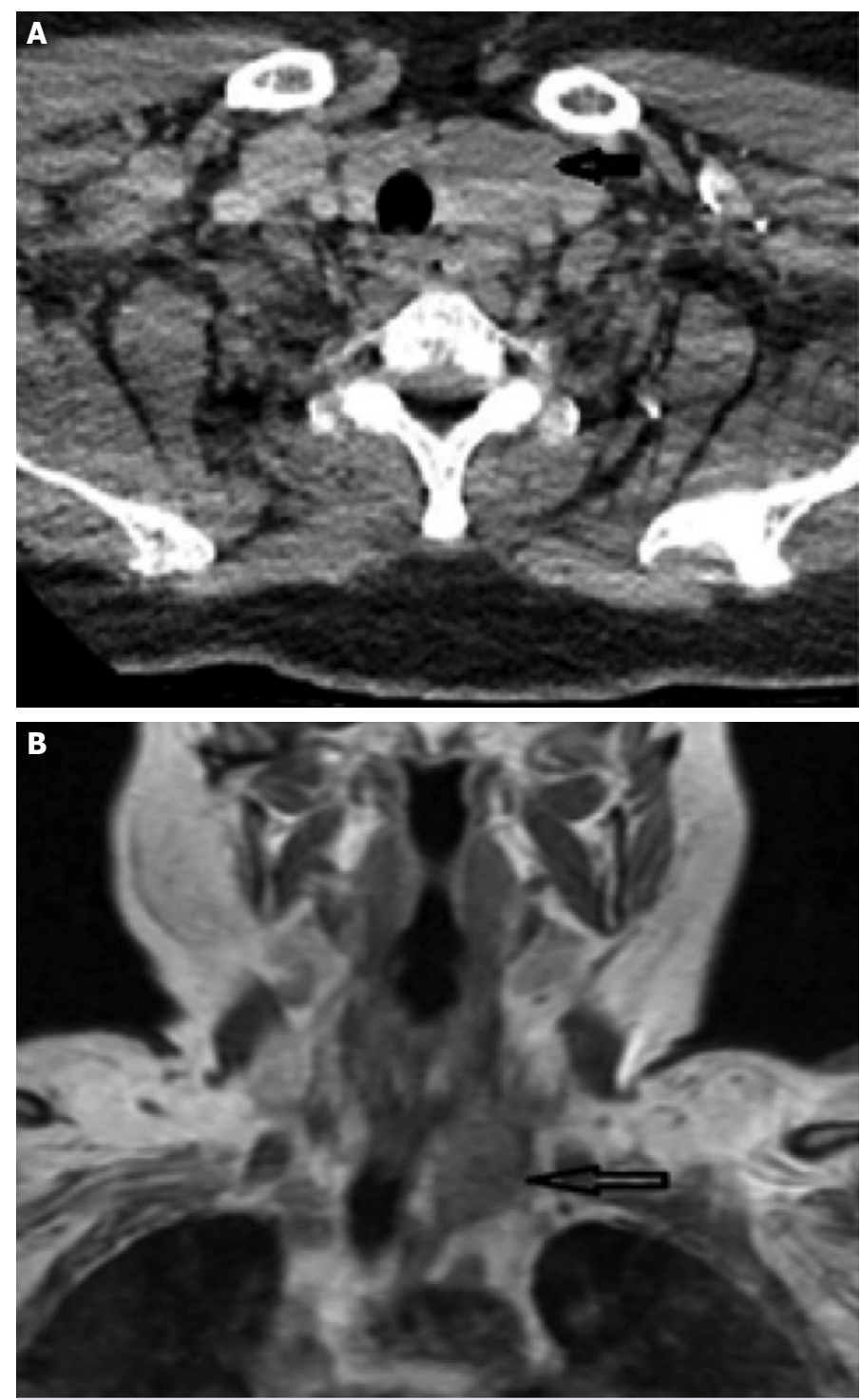

FIGURE 1. (A) Neck computed tomography (CT), axial plan, $4 * 2,5 * 3,5 \mathrm{~cm}$ size retrosternal mass, trachea pushed right side (arrow). (B) neck magnetic resonance imaging (MRI) coronal plan, contrast + , multilobular mass extending to the upper mediastinum (arrow).

18-month follow-ups. Written informed consent was obtained from the patient for this study.

\section{DISCUSSION}

Although EMC mostly develops in the parotid gland, some reports claim that it also occurs in the nasal cavity, paranasal sinus, nasopharynx, bronchus, lung, lacrimal gland, submandibular gland, and base of the tongue [2, $4,5]$. To our knowledge, no case of EMC in the supraclavicular region has been reported previously.

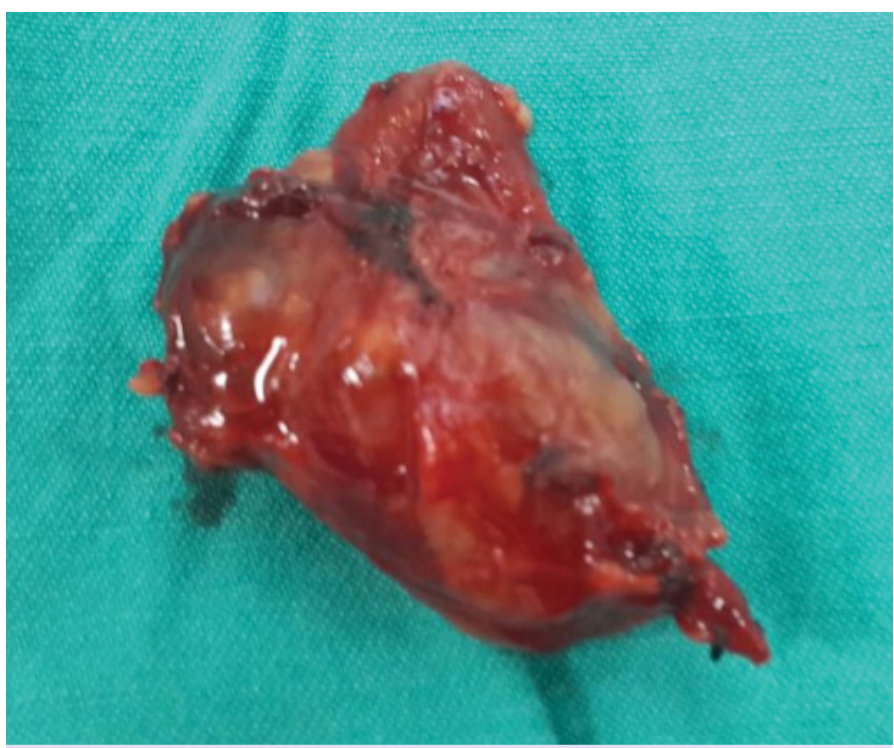

FIGURE2. Image of surgical excision specimen, nearly $6 \times 4 \times 3$ $\mathrm{cm}$ and multilobular.

EMC is a typically a low-grade malignant neoplasm, but in rare cases, the tumor may metastasize to distant sites. It has been highlighted that EMC develops more commonly in women and has a higher incidence in the fifth to eighth decades [2]. The symptoms of EMC vary depending on its anatomic position and size. When it encroaches at the cervical area, as found in our case, various symptoms may occur depending on the carcinoma's size, ranging from no symptoms to voice changes and respiratory obstruction. The major problems with our patient were dyspnea and swelling in the neck.

EMC is diagnosed using an optical microscope and using immunohistochemistry. On histology, EMC is characterized by the presence of tubules with two distinct types of cells. The main histological features of EMC are epithelial cells in the inner layer of the lumen and myoepithelial cells surrounding the outer layer [2, 6]. In immunohistochemical analysis, myoepithelial cells in the outer layer are positive for calponin, p63 protein, glial fibrillary acidic protein, S-100 protein, and SMA. Epithelial cells in the inner layer are positive for cytokeratin-7 and epithelial membrane antigen [2].

In our case, the outer myoepithelial cells tested positive for SMA and p63, while the inner epithelial cells were positive for cytokeratin; hence, EMC was diagnosed (Fig. 3, 4).

Other diseases that should be considered in the differential diagnosis of EMC are myoepithelial carcinoma, pleomorphic adenoma, and adenoid cystic carcinoma. 

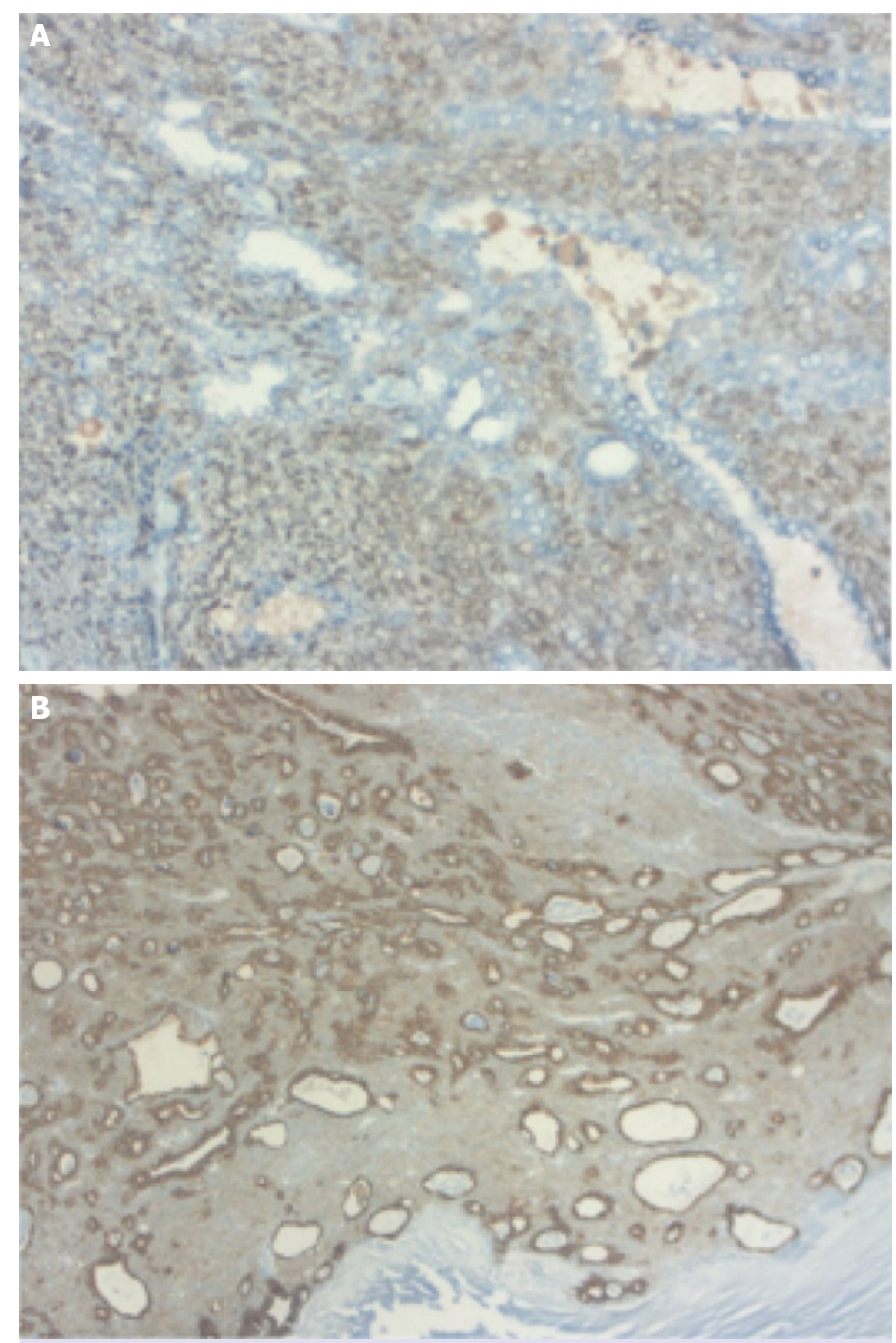

FIGURE 3. (A) Outer myoepithelial cells stain positive for smooth muscle actin (magnification 100), (B) inner luminal cells and outer myoepithelial cells positive for cytokeratin $5 / 6$ (magnification 100).

Similar local morphological features of EMC can be observed in adenoid cystic carcinoma and acinic cell carcinoma [7]. These carcinomas should be widely excised.

EMC is regarded as a low-grade malignancy tumor, and the treatment protocol involves wide surgical excision with secure clear margins [2]. Although postoperative radiotherapy is generally performed to reduce local recurrence, the effects of chemotherapy are not clear yet $[2,8]$. Tumors $>4 \mathrm{~cm}$ are often associated with local recurrence [2]. EMC is a low-grade malignancy, recurrence rate and metastasis account for 23 to $80 \%$ and 14 to $25 \%$ respectively. Most surgeons prefer wide excision with clear margins, followed by radiotherapy in selected cases to avoid recurrence [9]. Pierard et al. [10] proposed use in stabilization of pulmonary metastasis in these cases. In our case, we preferred chemoradiotherapy because of the tumor was $>4 \mathrm{~cm}$, and the surgical margin was positive.

As a conclusion, the presented case relates to an EMC originating from the supraclavicular region, where there has been no similar case reported previously. EMC is a low grade-malignancy, and the treatment protocol involves wide surgical excision. Postoperative chemoradiotherapy can use big size and positive margin.

Informed Consent: Written informed consent was obtained from the patient for the publication of the case report and the accompanying images.

Conflict of Interest: No conflict of interest was declared by the authors.

Financial Disclosure: The authors declared that this study did not have any financial support.

Authorship Contributions: Concept - IH, MS, AB, IO; Design IH, MS, AB, AK; Supervision - HK, IH, AK; Materials - MS, IH, AK; Data collection and/or processing - IH, MS, AB, IO; Analysis and/or interpretation - IO, IH; Literature search - AB, AK, HK, IH; Writing IH, MS; Critical review - IO, IH.

\section{REFERENCES}

1. Donath K, Seifert G, Schmitz R. Diagnosis and ultrastructure of the tubular carcinoma of salivary gland ducts. Epithelial-myoepithelial carcinoma of the intercalated ducts. [Article in German]. Virchows Arch A Pathol Pathol Anat 1972;356:16-31. [CrossRef]

2. Oh HJ, Do NY, Kee KH, Park JH. Epithelial-myoepithelial carcinoma arising from the subglottis: a case report and review of the literature. J Med Case Rep 2016;10:45. [CrossRef]

3. Patra SK, Panda NK, Saikia UN. Epithelial-myoepithelial carcinoma of the maxillary sinus: a rare case. Laryngoscope 2012;122:1579-81.

4. Konoglou M, Cheva A, Zarogoulidis P, Porpodis K, Pataka A, Mpaliaka $\mathrm{A}$, et al. Epithelial-myoepithelial carcinoma of the trachea-a rare entity case report. J Thorac Dis 2014;6 Suppl 1:S194-9.

5. Hattori K, Murai N, Kusano J, Takahashi Y. Bilateral epithelial-myoepithelial carcinoma of the parotid glands. Head Neck 2016;38:E73-5.

6. Peters P, Repanos C, Earnshaw J, Stark P, Burmeister B, McGuire L, et al. Epithelial-myoepithelial carcinoma of the tongue base: a case for the case-report and review of the literature. Head Neck Oncol 2010;2:4.

7. Simpson RH, Clarke TJ, Sarsfield PT, Gluckman PG. Epithelial-myoepithelial carcinoma of salivary glands. J Clin Pathol 1991;44:419-23.

8. Corio RL, Sciubba JJ, Brannon RB, Batsakis JG. Epithelial-myoepithelial carcinoma of intercalated duct origin. A clinicopathologic and ultrastructural assessment of sixteen cases. Oral Surg Oral Med Oral Pathol 1982;53:280-7. [CrossRef]

9. Erkan AN, Bal N, Caylakli F, Kiroğlu F. Epithelial-myoepithelial carcinoma of the submandibular gland: a case report. Kulak Burun Bogaz Ihtis Derg 2007;17:167-70.

10. Pierard S, Gregoire V, Weynand B, Machiels JP. Epithelial-myoepithelial carcinoma of the submandibular gland with symptomatic lung metastases treated with chemotherapy. Eur Arch Otorhinolaryngol 2006;263:1158-60. [CrossRef] 